\section{A common polymorphism in the 5' UTR of ERCC5 creates an upstream ORF that confers resistance to platinum-based chemotherapy}

Joanna Somers, ${ }^{1}$ Lindsay A. Wilson, ${ }^{1}$ John-Paul Kilday, ${ }^{2}$ Emilie Horvilleur, ${ }^{1}$ Ian G. Cannell, ${ }^{1,3}$ Tuija A.A. Pöyry, ${ }^{1}$ Laura C. Cobbold, ${ }^{1}$ Alexander Kondrashov, ${ }^{4}$ John R.P. Knight, ${ }^{1}$ Stéphanie Puget, ${ }^{5}$ Jacques Grill, ${ }^{6}$ Richard G. Grundy, ${ }^{2}$ Martin Bushell, ${ }^{1}$ and Anne E. Willis ${ }^{1}$

\begin{abstract}
${ }^{1}$ Medical Research Council Toxicology Unit, Leicester LE1 9HN, United Kingdom; ${ }^{2}$ Children's Brain Tumour Research Centre, The Medical School, University of Nottingham, Nottingham NG7 2UH, United Kingdom; ${ }^{3}$ David H. Koch Institute for Integrative Cancer Research, Massachusetts Institute of Technology, Cambridge, Massachusetts 02139, USA; ${ }^{4}$ School of Pharmacy, University of Nottingham, Nottingham NG7 2RD, United Kingdom; ${ }^{5}$ Departement de Neurochirugie Pédiatrique, Hôpital Necker, University Paris V Descartes, 75006 Paris, France; ${ }^{6}$ Department of Pediatric and Adolescent Oncology, Institut Gustave Roussy, 94805 Villejuif, France
\end{abstract}

We show that a common polymorphic variant in the ERCC5 5' untranslated region (UTR) generates an upstream ORF (uORF) that affects both the background expression of this protein and its ability to be synthesized following exposure to agents that cause bulky adduct DNA damage. Individuals that harbor uORF1 have a marked resistance to platinum-based agents, illustrated by the significantly reduced progression-free survival of pediatric ependymoma patients treated with such compounds. Importantly, inhibition of DNA-PKcs restores sensitivity to platinum-based compounds by preventing uORF1-dependent ERCC5 expression. Our data support a model in which a heritable $5^{\prime}$ noncoding mRNA element influences individuals' responses to platinumbased chemotherapy.

Supplemental material is available for this article.

Received March 10, 2015; revised version accepted August 14, 2015.

Many commonly used chemotherapeutic drugs, such as cisplatin, exert their cytotoxic affects by causing DNA damage in the form of intrastrand and interstrand crosslinks (Koberle et al. 2010; Galluzzi et al. 2011). In response to these lesions, cells initiate a complex series of signaling cascades that coordinate cell cycle arrest and DNA repair

[Keywords: DNA damage repair; ERCC5; protein synthesis; uORF] Corresponding author: aew5@le.ac.uk

Article published online ahead of print. Article and publication date are online at http://www.genesdev.org/cgi/doi/10.1101/gad.261867.115. Freely available online through the Genes \&) Development Open Access option. (collectively referred to as the DNA damage response [DDR]) (Bartek and Lukas 2007; Jackson and Bartek 2009). Importantly, the expression levels and activities of components of the DDR play a pivotal role in the response of tumors to therapy (Jackson and Bartek 2009; Helleday 2011).

Activation of the DDR by agents that cause bulky adduct damage, such as UV irradiation or cisplatin, increases the transcription of hundreds of genes, including genes directly involved in nucleotide excision repair (NER), the DNA repair pathway that removes these lesions (Rieger and Chu 2004; Boerma et al. 2005; da Costa et al. 2005). Additionally, in response to UV irradiation, many critical components of the NER pathway are also controlled at the level of translation (Deng et al. 2002; Powley et al. 2009). For translation initiation, the eukaryotic initiation factor $4 \mathrm{~F}$ (eIF4F) complex binds to the mRNA and recruits the ribosome and the ternary complex /comprised of eIF2, GTP, and tRNA imet $_{1}$, which delivers the initiator tRNA $_{\text {imet }}$ to the start codon (Sonenberg and Hinnebusch 2009). Formation of the ternary complex can by controlled by four upstream kinases (PERK, PKR, HRI, and GCN2) that phosphorylate eIF2 on the a subunit, causing sequestration of this protein in an inactive complex with its GEF eIF2B (Sonenberg and Hinnebusch 2009).

We showed previously that, in response to a nonlethal dose of UVB, signaling via DNA-PKcs to GCN2 results in a reduction in the global rate of protein synthesis mediated by an increase in the phosphorylation of eIF2a (Fig. 1A; Deng et al. 2002; Powley et al. 2009). However, despite the general repression of translation that occurs following UVB exposure, $\sim 8 \%$ of transcripts, including mRNAs encoding NER proteins, are recruited to translationally active polysomes concurrent with an increase in the translational efficiency of these mRNAs (Powley et al. 2009). The translation of proteins required for the DDR is dependent on sequence elements within the $5^{\prime}$ untranslated regions (UTRs) of their mRNAs that are referred to as upstream ORFs (uORFs) (Le Quesne et al. 2010; Somers et al. 2013). Under stress conditions, when increased eIF2 $\alpha$ phosphorylation lowers the availability of the eIF2 ternary complex, translation of some mRNAs containing uORFs are up-regulated, although the mechanisms by which uORFs function are not yet fully understood (for review, see Somers et al. 2013).

Given the role of uORFs in the DDR, one testable hypothesis would be that polymorphisms that create or remove upstream AUG codons (Deng et al. 2002; Calvo et al. 2009; Powley et al. 2009) in NER genes could contribute to the differential responses of patients to chemotherapeutic agents. Interestingly, ERCC5 (a structure-specific endonuclease that cleaves $3^{\prime}$ of the DNA adduct and is an indispensable core protein of the NER machinery) contains uORFs, one of which is generated by the polymorphic variant rs 751402 that is present in $35 \%$ of the white Caucasian population. Here we show that this uORF regulates the synthesis of ERCC5 following exposure to agents that cause bulky adduct DNA damage, that signaling through DNA-PKcs is required for the increased uORF-

(C) 2015 Somers et al. This article, published in Genes « Development, is available under a Creative Commons License (Attribution-NonCommercial 4.0 International), as described at http://creativecommons.org/ licenses/by-nc/4.0/. 
A

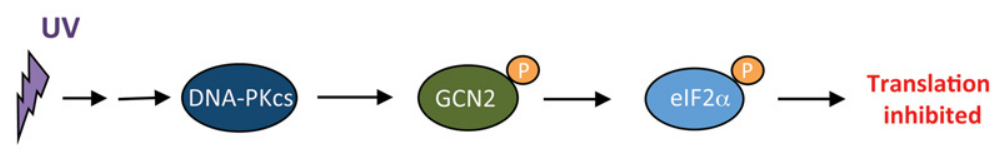

Bi

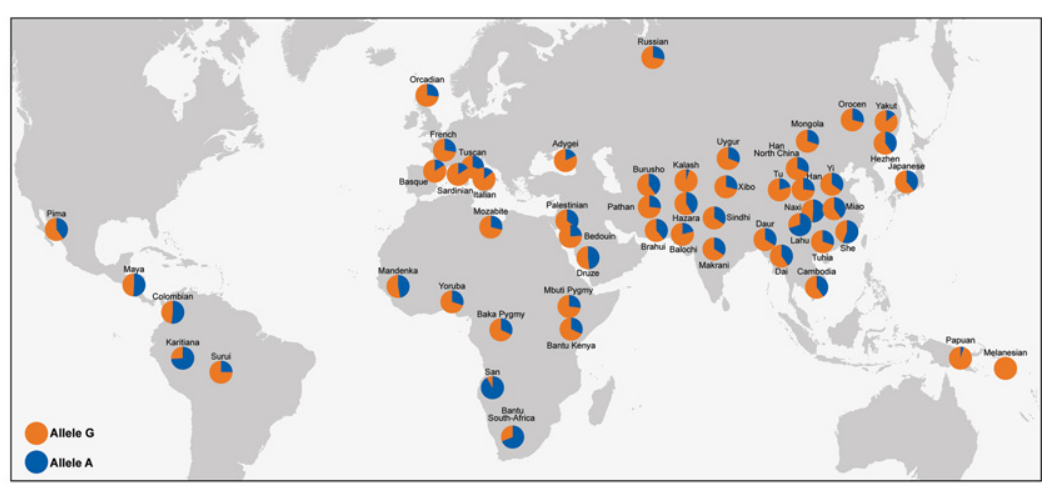

$\mathrm{Bi}$
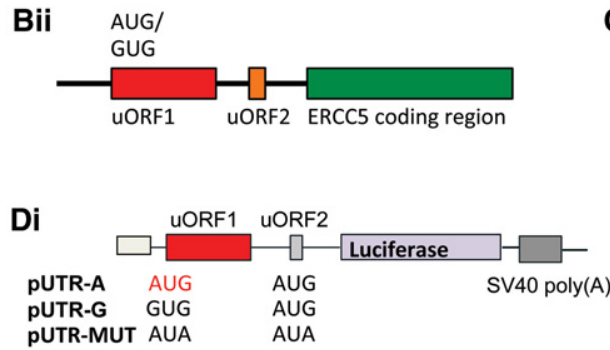

Dii

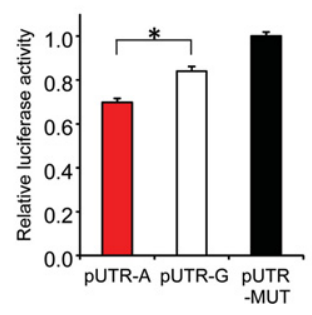

Ci Neuroblastoma cell lines
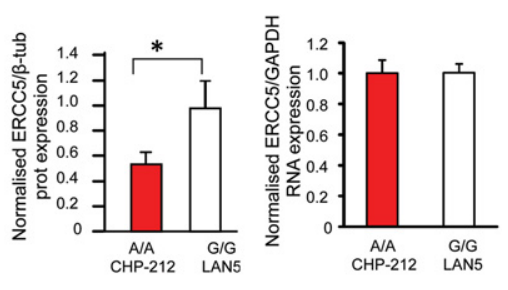

Cii B-cell lines
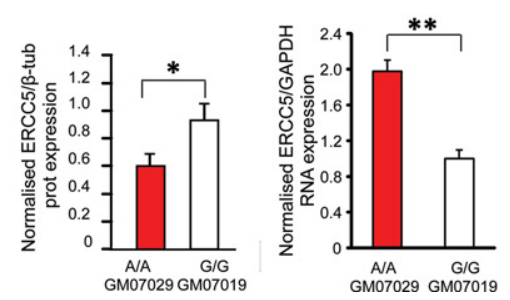

Figure 1. A polymorphism in a uORF controls ERCC5 translation. (A) Schematic diagram of signaling from bulky adduct damage to the inhibition of translation: When cells are exposed to bulky adduct damage (e.g., UVB light), there is a shutdown of translation and reprogramming of the translational machinery that permit the selective up-regulation of DNA repair enzymes at the level of translation. We showed previously that signaling from DNA-PKcs to phosphorylation of eIF2 $\alpha$ is essential for this response, since, in the presence of a DNA-PKcs inhibitor, in DNA-PKcs deficient cell lines, and following depletion of DNA-PKcs levels by siRNA, the translational shutdown and selective translational reprogramming that are part of the normal response are inhibited (Powley et al. 2009). (Bi) Global distribution of the polymorphism rs 751402. The derived " $\mathrm{A}$ " allele is present in $\sim 35 \%$ of white Caucasians. (Bii) Schematic representation of the uORFs present in ERCC5. (Ci,Cii) The levels of ERCC5 protein expression differ with genotype, with no corresponding changes in the levels of the mRNA. Levels of ERCC5 in neuroblastoma cell lines (derived from individual patients) or B-cell lines (derived from healthy individuals), each representing A/A or G/G genotypes, were determined by Western analysis. Parallel samples were taken, and the level of mRNA was assessed by quantitative PCR (qPCR). $\left({ }^{*}\right) P<0.05$; $\left(^{* *}\right) P<0.01$. (Di) Schematic diagram of the plasmids containing the alternative 5' UTRs of ERCC5. pUTR-A contains both uORF1 and uORF2, and pUTR-G contains uORF2. pUTR-MUT contains no uORFs (both uORF AUGs mutated to AUA). (Dii) HeLa cells were transfected with the plasmids indicated and a $\beta$-galactosidase transfection control. After $48 \mathrm{~h}$, cells were harvested and assayed for luciferase activity. pUTR-A caused the strongest inhibition of luciferase activity. (Black bars) pUTR-MUT; (red bars) pUTR-A; (white bars) pUTR-G. (*) $P<0.05$.

regulated translation of ERCC5 following cisplatin exposure, and, importantly, that $r s 751402$ is a prognostic indicator for poor progression-free survival of patients with

childhood ependymoma treated with platinum-containing compounds.

\section{Results and Discussion}

The 5' UTR of ERCC5 contains a functional uORF that is required for expression of the downstream cistron following bulky adduct DNA damage

The polymorphism rs 751402 , which is located in the $5^{\prime}$ UTR of ERCC5, is present in $35 \%$ of the white Caucasian population (Fig. 1Bi). This polymorphism generates a uORF (termed uORF1) (Fig.1Bii). The two variants are referred to as the "G" allele (no uORF1) or the "A" allele (uORF1). uORF1 lies 243 bases upstream of a second UORF (termed uORF2) and 420 bases upstream of the physiological AUG start codon (Supplemental Fig. 1A).

To test the hypothesis that the polymorphism could be associated with altered expression of endogenous ERCC5, Western blot analysis was carried out on either $A / A$ or $G / G$ cell lines derived from patients with neuroblastoma or B cells derived from healthy individuals. The data show that cell lines homozygous for the ERCC5 " $\mathrm{A}$ " allele expressed a significantly lower level of ERCC5 protein with no such difference detectable in the levels of RNA expression (Fig. 1Ci,Cii). We reasoned that the difference in expression of ERCC5 from these transcripts could be due to the presence of the additional uORF1, and, in support of this, sequencing of the entire $5^{\prime}$ UTR of the G/G or A/A cell lines revealed no other sequence differences (Supplemental Fig. 1B). To investigate the impact of the rs751402 polymorphism upon translation of the downstream cistron in a cell culture-based system, the 5' UTR of ERCC5 was subcloned upstream of the luciferase coding sequence to generate three constructs: pUTR-A (containing both uORF1 and uORF2), pUTR-G (containing uORF2), and a control construct, pUTR-MUT, in which the $5^{\prime}$ UTR of ERCC5 contained no uORFs (both AUGs were mutated to AUA) (Fig. 1Di). The plasmids were transfected into HeLa cells, and the luciferase activity was determined. These data show that uORF2-containing transcripts showed repressed translation relative to pUTR-MUT; however, uORF1 (rs751402 SNP pUTR-A) led to further inhibition (Fig. 1Dii). To ensure that translation was initiated at the AUG codons found at the start of $\mathrm{UORF} 1$ and $\mathrm{UORF} 2$, the luciferase constructs containing 
the 5' UTRs of the two variants of the ERCC5 sequence were modified such that the AUGs of the uORFs were in-frame with the luciferase start codon (Supplemental Fig. 1Ci). RNAs generated from these vectors were used to prime rabbit reticulocyte lysates, and the data show that ribosomes can recognize and initiate from the AUG codons in both uORFs (Supplemental Fig. 1Cii).

To confirm whether the ERCC5 uORF1 translationally regulates the expression of a reporter protein in response to bulky adduct DNA damage, cells were transfected with the reporter constructs and then treated with cisplatin (Fig. 2Ai) or UVB (Fig. 2Aii). In each case, the translation from the construct with no uORFs (pUTR-MUT) or only uORF2 (pUTR-G) was repressed by the treatments (consistent with a global decrease in translation rates due to

Ai
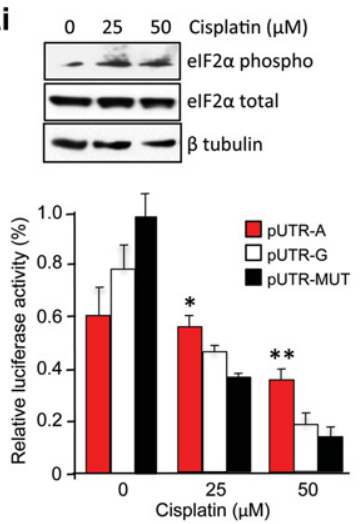

B

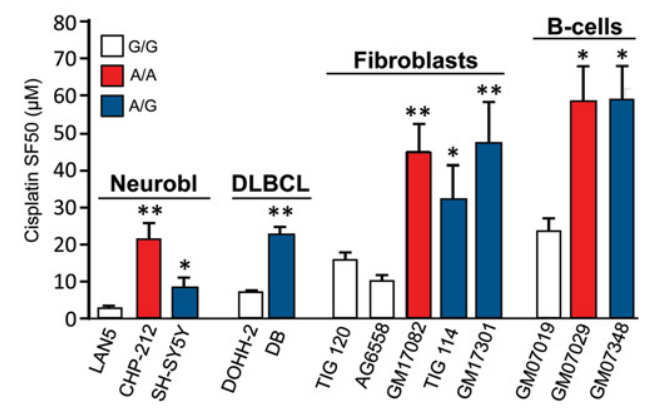

Figure 2. The $5^{\prime}$ UTR of ERCC5 contains a uORF that promotes translation in response to bulky adduct DNA damage. (Ai,Aii) HeLa cells were transfected with the plasmids indicated and then exposed to cisplatin (Ai) or UVB (Aii) and harvested at the times indicated. Cells were then lysed, and the luciferase activity was determined. When exposed to DNA damage, cells containing the pUTR-A plasmid show significantly higher luciferase activity. (Black bars) pUTR-MUT; (red bars) pUTR-A; (white bars) pUTR-G. $\left({ }^{*}\right) P<0.05$; $(* *) P<0.01 ;\left(^{* * *}\right) P<0.001$. (B) Cisplatin SF50 values. WST1 assays were performed on a panel of cell lines. Cell lines derived from patients with neuroblastoma were either LAN5 (G/G), CHP-212 (A/A), or SH-SY5Y (A/G). Cell lines derived from patients with diffuse large B-cell lymphoma (DLBCL) were either DOHH-2 (G/G) or DB $(\mathrm{A} / \mathrm{G})$. Fibroblasts derived from healthy individuals were either AG06558 (G/G), TIG120 (G/G), GM17082 (A/A), GM17301 (A/G), or TIG114 (A/G). B cells derived from healthy individuals were GM07019 (G/G), GM07029 (A/A), or GM07348 (A/G). These cell lines were treated with a range of cisplatin concentrations (see Supplemental Fig. 2) for $24 \mathrm{~h}$ (except B cells that were treated for $16 \mathrm{~h}$ ), and SF50s (the cisplatin concentrations required to kill 50\% of a cell population) were calculated by a logarithmic regression. The graph shows the SF50 mean values and standard error of the mean from three independent experiments. For the 13 cell lines used, there was a significantly lower survival of cells that were homozygous for the " $\mathrm{G}$ " allele. phosphorylation of eIF2 $\alpha$ ). However, synthesis from the rs751402 SNP pUTR-A construct remained significantly higher, demonstrating that uORF1 augments translation following DNA damage (Fig. 2A).

These data strongly suggest that $\mathrm{UORF} 1$ is required for expression of the downstream cistron following exposure to compounds that elicit bulky adduct DNA damage.

\section{ERCC5 transcripts that harbor uORF1 confer resistance to cisplatin exposure}

Since platinum-based chemotherapy is used as a frontline treatment for a range of tumors (Galluzzi et al. 2011), we hypothesized that the polymorphism, by facilitating ERCC5 protein expression, could affect the sensitivity of cells to these compounds. Thirteen cell lines representative of the three different genotypes, including cell lines derived from patients with neuroblastoma and diffuse large B-cell lymphoma (DLBCL) and from healthy individuals of fibroblast and B-cell origin, were incubated with increasing doses of cisplatin. The percentage of cell survival was determined in each case by using WST1 assays (Supplemental Fig. 2A-E), and, using these data, SF50s (the cisplatin concentrations required to reduce $50 \%$ of the cell population) were calculated by a logarithmic regression. In each group of cell types, there was relatively higher survival of those that contained the " $\mathrm{A}$ " allele (A/A or A/G) when compared with cells that are homozygous for the "G" allele (Fig. 2B).

To assess the effects that uORF1 had on endogenous ERCC5 expression in response to cisplatin exposure, neuroblastoma and B-cell lines representative of all three genotypes were used. All genotypes showed substantial reduction in global protein synthesis rates with cisplatin treatment, as assessed by methionine incorporation (Fig. 3Ai, Aii). To determine how cisplatin exposure affected ERCC5 expression among the different genotypes, Western blot analysis and quantitative PCR (qPCR) were performed in parallel (Fig. 3Bi,Bii,Ci,Cii). In all cell lines, there was an increase in eIF $2 \alpha$ phosphorylation following exposure to cisplatin (Fig. 3Bi,Ci), consistent with the reduction in global protein synthesis rates. However, in cell lines that contain the ERCC5 transcripts with uORF1 (both A/A and A/G), there was maintenance of ERCC5 protein expression after exposure to cisplatin. In contrast, cells homozygous for the " $\mathrm{G}$ " allele showed a decrease in expression of this protein with an increasing dose of cisplatin (Fig. 3Bi,Ci). There was no significant increase in the levels of ERCC5 mRNA (Fig. 3Bii,Cii). Consistent with an enhanced translation rate, we show that the " $\mathrm{A}$ " allele ERCC5 transcripts were specifically maintained on polysomes (actively translating ribosomes) in response to cisplatin, while " $\mathrm{G}$ " allele transcripts shifted toward lighter polysomes (less actively translating ribosomes) in heterozygote cell lines (Supplemental Fig. 3). Pulse-labelled immunoprecipitations to examine ERCC5's half-life confirmed that the loss of ERCC5 protein expression after cisplatin treatment is solely due to translational inhibition (Supplemental Fig. 4).

To confirm the link between induction of ERCC5 and repair of cisplatin-induced DNA damage, competitive ELISAs were carried out to assess the degree of cisplatin adducts that remained in cells derived from neuroblastomas (Fig. 3Biii) or B cells (Fig. 3Ciii) at 24 or $16 \mathrm{~h}$ of exposure to this compound, respectively. The data show that significantly more competition (indicating higher 
Ai

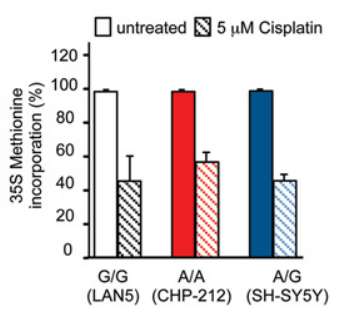

$\mathrm{Bi}$

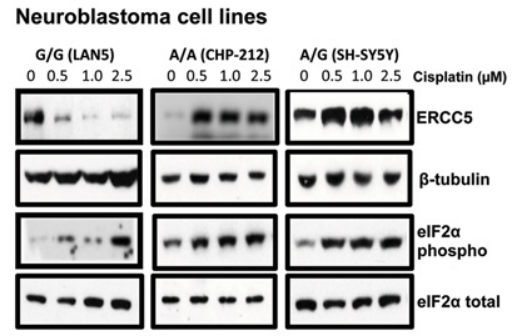

Bii

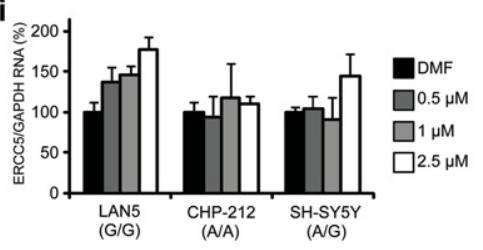

Biii

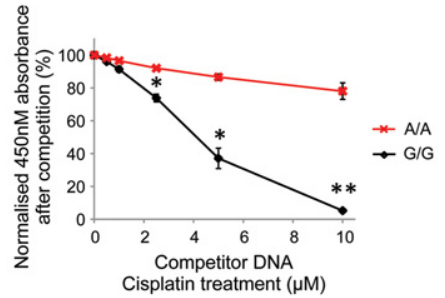

Figure 3. A uORF in the $5^{\prime}$ UTR of ERCC5 promotes resistance to cisplatin in vitro. (Ai,Aii) Neuroblastoma cell lines (Ai) or B-cell lines (Aii) derived from healthy individuals for all three rs751402 genotypes were treated with cisplatin at the doses shown, and methionine incorporation was measured to assess the degree of inhibition of global protein synthesis rates. There were no significant differences in the degrees of inhibition of protein synthesis between the three $\mathrm{B}$-cell lines or the three neuroblastoma-derived cell lines. (Solid bars) Control conditions; (hatched bars) cells treated with cisplatin. (Bi-Biii,Ci-Ciii) The three neuroblastoma cell lines (Bi-Biii) or the three B-cell lines (Ci-Ciii) of each ERCC5 5' UTR rs751402 genotype were treated with the doses of cisplatin shown, and protein and RNA samples were obtained. (Bi,Ci) Protein samples were separated by SDS-PAGE and immunoblotted. The data show that, in all cases, eIF2 $\alpha$ is phosphorylated by treatment of cells with cisplatin with no change in the total levels of eIF2 $\alpha$. In each case, with increasing doses of cisplatin in the cell lines that were homozygous for the " $\mathrm{G}$ " allele, there was a marked decrease in ERCC5. In contrast, when the cells lines that contain the ERCC5 $5^{\prime}$ UTR "A" allele (either the homozygous or heterozygous cell lines) were treated with cisplatin, the expression of ERCC5 protein was maintained. (Bii,Cii) The level of ERCC5 mRNA was assessed by qPCR, and no significant increases were detected. (Biii,Ciii) A competitive ELISA was used to measure platinum adduct levels in cisplatin-treated neuroblastoma and B cells. Cells were treated with cisplatin at the doses shown. DNA was then extracted, and equal concentrations were used to perform a competitive ELISA against a standard of platinated DNA with the monoclonal antibody (CP9/19) that recognizes guanine intrastrand cross-links formed by cisplatin. Plotted is the mean absorbance normalized to competition with DMF DNA $(100 \%)$ for the neuroblastoma cells (Biii) or B cells (Ciii). In both cell lines, the G/G genotype provided significantly more competition, demonstrating a higher adduct level. $\left(^{*}\right) P<0.05$; $\left(^{* *}\right) P<0.01$.

cisplatin adduct levels) was provided from the cell lines whose ERCC5 transcripts lack the uORF1 (G/G), implying that these cells have slower repair rates (Fig. 3Biii,Ciii).

Collectively, these data suggest that tumors that arise in individuals that harbor at least one ERCC5 " $\mathrm{A}$ " allele (rs751402 uORF1) are likely to be refractory to plati- num-based chemotherapy as a result of the translational up-regulation of this protein.

\section{Translational control of ERCC5 is downstream from DNA-PKcs}

Following bulky adduct DNA damage, signaling through DNA-PKcs / a critical DNA damage kinase) is required for the selective translational activation of NER enzymes in response to UVB irradiation, and phosphorylation of eIF $2 \alpha$ links DNA damage sensing to protein synthesis regulation (Powley et al. 2009). Therefore, we hypothesized that resistant " $\mathrm{A}$ " allele-expressing cells could be sensitized to cisplatin by DNA-PKcs inhibition (Supplemental Fig. 5A). B cells were pretreated with the DNA-PKcs inhibitor Nu7441 (Supplemental Fig. 5B; Hardcastle et al. 2005) and exposed to $50 \mu \mathrm{M}$ cisplatin, and survival assays were performed. The data show that, in the presence of the DNA-PKcs inhibitor, the differential response to cisplatin was ablated and became independent of the genotype (Fig. 4A). Western blot analysis confirmed inhibition of eIF $2 \alpha$ phosphorylation by Nu7441 and attenuation of the induction of ERCC5 in rs751402 "A" allele-expressing cells (Fig. 4B; Supplemental Fig. 5Ci,Cii, Ciii), with no such change in the ERCC5 RNA levels (Fig. 4C). To confirm a role for eIF2 $\alpha$ phosphorylation in this process, cells that contained the "A" allele of ERCC5 were transfected with plasmids encoding the eIF2 $\alpha$ phosphatase GADD34 (Supplemental Fig. 5A). The data show that direct inhibition of eIF $2 \alpha$ phosphorylation was sufficient to inhibit the increase in ERCC5 expression after cisplatin exposure, strongly supporting a role for eIF2 $\alpha$ in this process (Supplemental Fig. 5D).

\section{The polymorphism is prognostic for progression-free survival for individuals with childhood ependymoma following platinum- based therapy}

The in vitro cisplatin resistance of the "A" allele variant of ERCC5 led us to hypothesize that cancer patients who carried the " $\mathrm{A}$ " allele would be more refractory to platinum chemotherapy due to relatively high rates of repair of platinum-DNA adducts within tumors. Testing this hypothesis at the clinical level required a tumor type that fulfilled the following important criteria: The primary adjuvant therapy was platinum-based and was not confounded by the addition of other adjuvant 
A

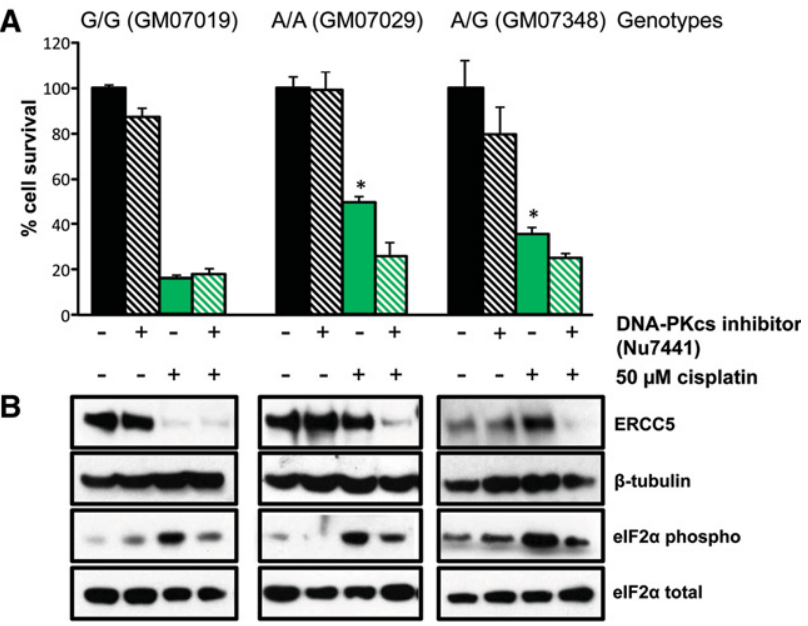

C

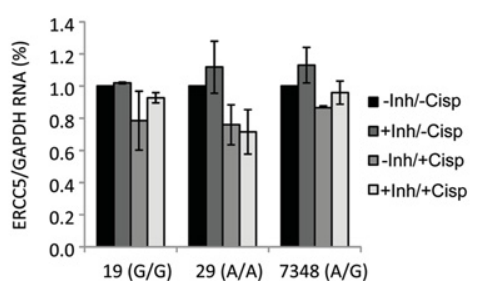

Figure 4. Otherwise resistant cells are sensitized to cisplatin treatment by inhibiting DNA-PKcs activity. (A) The three B-cell lines were incubated with either DMSO/DMF (solvent control; black bars), $1 \mu M$ DNA-PKcs inhibitor Nu7441 (black hatched bars), $50 \mu \mathrm{M}$ cisplatin (green bars), or a combination of Nu7441 and cisplatin (green hatched bars), and the survival rates were determined. The data show that cells that contained the " $\mathrm{A}$ " allele had a statistically significant higher survival rate after cisplatin treatment. However, pretreatment with $\mathrm{Nu} 7441$ rendered all cell genotypes equally sensitive to cisplatin. $(*) P<0.05$. (B) Extracts were generated from cells treated as above and were separated by SDS-PAGE and immunoblotted with the antibodies shown. The data show that, in the presence of the DNA-PKcs inhibitor and cisplatin, there is a decrease in the phosphorylation of eIF2 $\alpha$ and a corresponding decrease in the level of

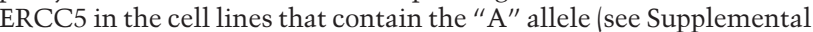
Fig. 5 for quantification). (C) The level of ERCC5 mRNA was assessed from parallel samples by qPCR, and no changes corresponding to differential protein expression were detected.

treatment. For these salient reasons, we chose to study the outcomes in ependymoma in very young children treated in two clinical trials (Grill et al. 2001; Grundy et al. 2007). Ependymoma is the third most common malignant brain tumor in children, accounting for $12 \%$ of all brain tumors, and the 5 -year survival rates range from $39 \%$ to $64 \%$ (Kilday et al. 2009). Early childhood ependymoma also exhibits low genetic heterogeneity (Supplemental Material). The current frontline therapy for ependymoma is surgical resection followed by radiotherapy, which has reasonable response rates. However, this can lead to significant sequelae for the developing CNS, such as neuropsychological and cognitive defects later in life. Therefore, efforts have been made to use adjuvant chemotherapy based on platinum agents (cisplatin and carboplatin) in place of radiation in very young patients (Grill et al. 2001; Grundy et al. 2007). The distribution of the ERCC5 rs 751402 polymorphism in ependymoma patients was examined using allele-specific PCR on genomic DNA extracted from 55 post-operative frozen tumor tissue samples, and progression-free survival rates were analyzed (Fig. 5; Supplemental Tables 1,2).
These data show that patients that express an " $\mathrm{A}$ " allele (uORF1) ERCC5 transcript have significantly reduced progression-free survival $(P=0.016)$ and multivariate hazard ratio of $3.63(95 \%$ CI [confidence interval]; 1.69 and 7.76$)$ (Fig. 5; Supplemental Table 1). The rs 751402 genotype did not affect the overall survival of ependymoma patients $(P=0.108)$, most likely because patients who failed to respond to primary chemotherapy subsequently received radiotherapy, which creates double-strand breaks-a form of DNA damage not repaired by the NER pathway.

Overall, these data would strongly suggest that the rs 751402 polymorphism is an independent prognostic factor for progression-free survival of platinum-treated ependymoma in early childhood patients.

In our study, we provided mechanistic data to show for the first time how a polymorphism in a $5^{\prime}$ UTR can create an RNA regulatory element that influences cell fate. The data presented here have very important implications for the treatment of ependymoma with platinum-based compounds. Given the prevalence of polymorphic variants that create or remove uORFs in humans /Calvo

A

\begin{tabular}{|c|c|c|c|c|c|c|}
\hline \multirow[t]{2}{*}{ Factor } & \multicolumn{3}{|c|}{ Univariate } & \multicolumn{3}{|c|}{ Multivariate } \\
\hline & HR & $95 \% \mathrm{Cl}$ & $\mathbf{P}$ & HR & $95 \% \mathrm{Cl}$ & $\mathbf{P}$ \\
\hline $\begin{array}{l}\text { Location } \\
\text { ST }(n=10) \\
\operatorname{PF}(n=45)\end{array}$ & $\begin{array}{c}1 \\
0.75\end{array}$ & $0.33-1.71$ & 0.492 & - & - & - \\
\hline $\begin{array}{l}\text { WHO grade (1 MD) } \\
\text { II }(n=15) \\
\text { III }(n=39)\end{array}$ & $\begin{array}{c}1 \\
2.25\end{array}$ & $1.03-4.94$ & 0.042 & $\begin{array}{c}1 \\
3.31\end{array}$ & $1.43-7.65$ & 0.005 \\
\hline $\begin{array}{l}\text { Sex } \\
\text { Female }(n=17) \\
\text { Male }(n=38)\end{array}$ & $\begin{array}{c}1 \\
0.67\end{array}$ & $0.34-1.32$ & 0.252 & - & 1.10 & - \\
\hline $\begin{array}{l}\text { Surgery } \\
C R(n=38) \\
\operatorname{IR}(n=17)\end{array}$ & $\begin{array}{c}1 \\
1.08\end{array}$ & $0.55-2.11$ & 0.831 & - & - & - \\
\hline $\begin{array}{l}\text { Genotype } \\
G / G(n=40) \\
A / A \text { or } A / G(n=15)\end{array}$ & $\begin{array}{c}1 \\
2.28\end{array}$ & $1.13-4.58$ & 0.021 & $\begin{array}{c}1 \\
3.63\end{array}$ & $1.69-7.76$ & 0.001 \\
\hline
\end{tabular}

B Ependymoma cohort $(n=55)$

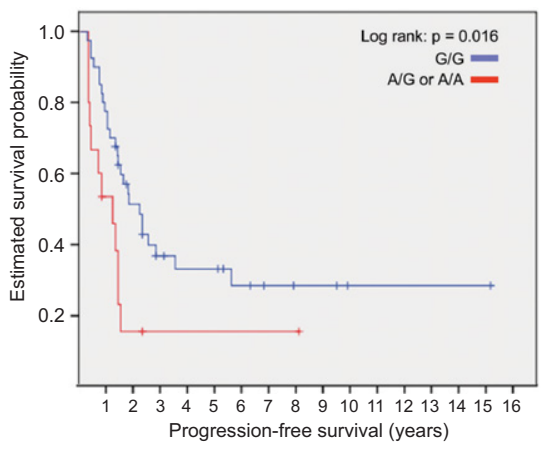

Figure 5. The polymorphism in ERCC5 is prognostic for sensitivity to platinum-based chemotherapy in early childhood ependymoma. (A) Clinicopathological data from primary ependymoma patients obtained from Children's Cancer and Leukaemia Group (CCLG) or Société Française d'Odontologie Pédiatrique (SFOP). All 55 children were below 5 years of age at diagnosis and had been treated only with primary post-operative platinum chemotherapy (cisplatin/carboplatin) (Grill et al. 2001; Grundy et al. 2007). This was in adherence to two concordant European pediatric clinical trials: CCLG CNS9204 (Grundy et al. 2007) ( $n=41)$ and Baby Brain SFOP (BBSFOP) (Grill et al. 2001) $(n=14)$. Probability $(P)$ values for univariate and multivariate survival analysis were obtained by the Cox proportional hazard model. (PF) Posterior fossa; (ST) supratentorial; (IR) incomplete resection; (CR) complete resection; (HR) hazards ratio; (95\% CI) 95\% confidence interval; (MD) missing data. (B) Kaplan-Meier plot of progression-free survival of ependymoma patients treated with platinum chemotherapy that were homozygous for the " $\mathrm{G}$ " allele (blue line) or contained the " $\mathrm{A}$ " allele (A/G or $\mathrm{A} / \mathrm{A}$; red line). 
et al. 2009), there may well be other such elements that have the potential to modify an individual's sensitivity to a range of agents. These warrant further investigation.

\section{Materials and methods}

\section{Cell culture}

HeLa cells were cultured as described (Powley et al. 2009). TIG fibroblasts were from the Japanese Collection of Research Bioresources (JCRB) and were cultured according to the JCRB Cell Bank (http://cellbank.nibio.go. jp). B cells and fibroblasts were from Coriell Cell Repositories and were cultured according to the Coriell Cell Repositories site (http://ccr.coriell.org). Neuroblastoma cells were from American Type Culture Collection (except for the LAN5 cell line, which was obtained from Charles-Henry Gattolliat, Institute Gustave Roussy, Villejuif, France). DLBCL cells were a gift from Professor M. Dyer, University of Leicester. B cells naturally form clumps in culture that can induce cellular stress signaling pathways. To minimize these effects, clumps were dispersed during treatments and $1 \mathrm{~h}$ prior to harvest.

\section{Cells treatments}

Cells were exposed to UVB as described (Powley et al. 2009). Cisplatin was dissolved in DMF and added to B cells or HeLa for $16 \mathrm{~h}$ or to neuroblasto$\mathrm{ma}, \mathrm{DLBCL}$, and fibroblasts for $24 \mathrm{~h}$. Nu7441 (1 $\mathrm{\mu M})$ was added $30 \mathrm{~min}$ prior to cisplatin. All experiments were performed on at least three separate occasions.

\section{Transient transfections and reporter gene assays}

Transient transfections and measurements of luciferase activity were as described (Kong et al. 2008; Powley et al. 2009). Luciferase values were expressed relative to the transfection control $\beta$-galactosidase, or, for cisplatin and UVB DNA damage treatments, the values were expressed relative to luciferase RNA levels determined by qPCR. All values were normalized to the level of the "no uORFs" mutant pUTR-MUT, which was set to a value of 1.0. All experiments were performed on at least three independent occasions.

Additional details about the Materials and Methods are provided in the Supplemental Material.

\section{Acknowledgments}

We acknowledge the help of Nicole Brousse from the Tumor Bank from Necker Sick Children Hospital. This work was supported by funding from Cancer Research UK (to A.K., J.S., and L.A.W.); the Biotechnology and Biological Sciences Research Council (professorial fellowship to A.E.W.); the Medical Research Council (Senior Fellowship to M.B., and Medical Research Council program funding to A.E.W.); and the Societe Francaise des Cancers de 1'Enfant/Enfants et Sante, Etoile de Martin, and Fondation Carrefour (to J.G. and S.P.). Ependymoma research within the Children's Brain Tumour Research Centre is funded by the Joe Foote Foundation. J.-P.K. is a James Tudor Clinical Research Fellow in Paediatric Neuro-Oncology at the Children's Brain Tumour Research Centre, United Kingdom.

\section{References}

Bartek J, Lukas J. 2007. DNA damage checkpoints: from initiation to recovery or adaptation. Curr Opin Cell Biol 19: 238-245.
Boerma M, van der Wees CGC, Vrieling H, Svensson JP, Wondergem J, van der Laarse A, Mullenders LHF, van Zeeland AA. 2005. Microarray analysis of gene expression profiles of cardiac myocytes and fibroblasts after mechanical stress, ionising or ultraviolet radiation. $B M C$ Genomics 6: 6.

Calvo SE, Pagliarini DJ, Mootha VK. 2009. Upstream open reading frames cause widespread reduction of protein expression and are polymorphic among humans. Proc Nat1 Acad Sci 106: 7507-7512.

da Costa RMA, Riou L, Paquola A, Menck CFM, Sarasin A. 2005. Transcriptional profiles of unirradiated or UV-irradiated human cells expressing either the cancer-prone $\mathrm{XPB} / \mathrm{CS}$ allele or the noncancerprone XPB/TTD allele. Oncogene 24: 1359-1374.

Deng J, Harding HP, Raught B, Gingras AC, Berlanga J, Scheuner D, Kaufman RJ, Ron D, Sonenberg N. 2002. Activation of GCN2 in UV-irradiated cells inhibits translation. Current Biol 12: 1279-1286.

Galluzzi L, Senovilla L, Vitale I, Michels J, Martins I, Kepp O, Castedo M, Kroemer G. 2011. Molecular mechanisms of cisplatin resistance. Oncogene 31: 1869-1883.

Grill J, Le Deley MC, Gambarelli D, Raquin MA, Couanet D, Pierre-Kahn A, Habrand JL, Doz F, Frappaz D, Gentet JC, et al. 2001. Postoperative chemotherapy without irradiation for ependymoma in children under 5 years of age: a multicenter trial of the French Society of Pediatric Oncology. J Clin Oncol 19: 1288-1296.

Grundy RG, Wilne SA, Weston CL. 2007. Primary postoperative chemotherapy without radiotherapy for intracranial ependymoma in children: the UKCCSG/SIOP prospective study. Lancet Oncol 8: 761-761.

Hardcastle IR, Cockcroft X, Curtin NJ, El-Murr MD, Leahy JJ, Stockley M, Golding BT, Rigoreau L, Richardson C, Smith GC, et al. 2005. Discovery of potent chromen-4-one inhibitors of the DNA-dependent protein kinase (DNA-PK) using a small-molecule library approach. I Med Chem 48: 7829-7846.

Helleday T. 2011. The underlying mechanism for the PARP and BRCA synthetic lethality: clearing up the misunderstandings. Mol Oncol 5: 387-393.

Jackson SP, Bartek J. 2009. The DNA-damage response in human biology and disease. Nature 461: 1071-1078.

Kilday J-P, Rahman R, Dyer S, Ridley L, Lowe J, Coyle B, Grundy R. 2009. Pediatric ependymoma: biological perspectives. Mol Cancer Res 7: 765-786.

Koberle B, Tomicic MT, Usanova S, Kaina B. 2010. Cisplatin resistance: preclinical findings and clinical implications. Biochim Biophys Acta 1806: $172-182$.

Kong YW, Cannell IG, de Moor CH, Hill K, Garside PG, Hamilton TL, Meijer HA, Dobbyn HC, Stoneley M, Spriggs KA, et al. 2008. The mechanism of micro-RNA-mediated translation repression is determined by the promoter of the target gene. Proc Natal Acad Sci 105: 8866-8871.

Le Quesne J, Spriggs K, Bushell M, Willis A. 2010. Dysregulation of protein synthesis and disease. J Pathol 220: 140-151.

Powley I, Kondrashov A, Young LA, Dobbyn HC, Hill K, Cannell IG, Stoneley M. 2009. Translational reprogramming following UVB irradiation is mediated by DNA-PKcs and allows selective recruitment to the polysomes of mRNAs encoding DNA repair enzymes. Genes Dev 23: 1207-1220.

Rieger KE, Chu G. 2004. Portrait of transcriptional responses to ultraviolet and ionizing radiation in human cells. Nucleic Acids Res 32: 4786-4803.

Somers J, Pöyry T, Willis AE. 2013. A perspective on mammalian upstream open reading frame function. Int J Biochem Cell Biol 45: 1690-1700.

Sonenberg N, Hinnebusch AG. 2009. Regulation of translation initiation in eukaryotes: mechanisms and biological targets. Cell 136: 731745 


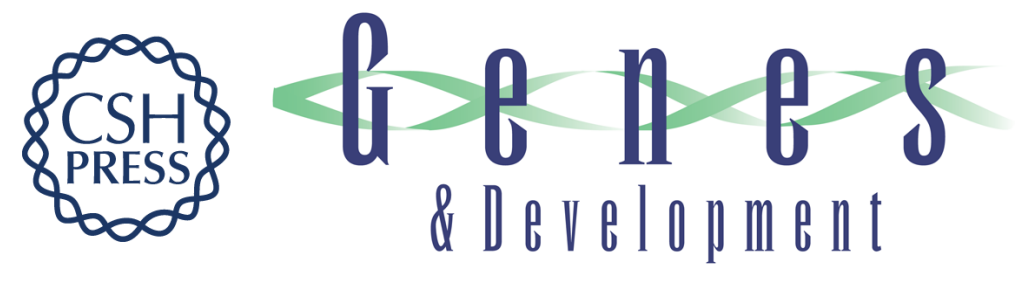

\section{A common polymorphism in the 5' UTR of ERCC5 creates an upstream ORF that confers resistance to platinum-based chemotherapy}

Joanna Somers, Lindsay A. Wilson, John-Paul Kilday, et al.

Genes Dev. 2015, 29: originally published online September 3, 2015

Access the most recent version at doi:10.1101/gad.261867.115

\section{Supplemental http://genesdev.cshlp.org/content/suppl/2015/09/03/gad.261867.115.DC1 Material}

References This article cites 19 articles, 4 of which can be accessed free at: http://genesdev.cshlp.org/content/29/18/1891.full.html\#ref-list-1

Creative This article, published in Genes \& Development, is available under a Creative Commons Commons License (Attribution-NonCommercial 4.0 International), as described at License http://creativecommons.org/licenses/by-nc/4.0/.

Email Alerting Receive free email alerts when new articles cite this article - sign up in the box at the top Service right corner of the article or click here.

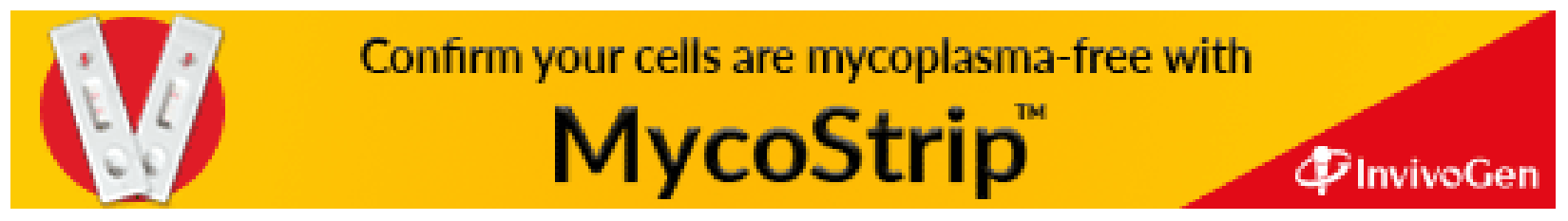

